\title{
A Simple Heliodon System for Horizontal Placed Models
}

\author{
* Dr. Maged G., Mikhael ', Mr. Mostafa, Metwaly ${ }^{2}$
}

2 Canadian International College (ClC), Egypt

\section{ART I CLEINF O:}

Article history:

Received 2 August 2017

Accepted 23 August 2017

Available online 12 October 2017

\section{Keywords:}

Heliodon;

Solar path tracking;

Sun's position;

Daylight.

This work is licensed under a Creative Commons Attribution

NonCommercial - NoDerivs 4.0. "CC-BY-NC-ND"

IE mail: maged george@cic-cairo.com ,E mail: mostafa metwaly@cic-cairo.com

\begin{abstract}
A B S T R A C T
Most probably, all our buildings are affected by sunlight. Hence, the ignorance of the sun's impact results in overheating, glare, and missed opportunities for the positive use of daylight, leading to wasted energy. Heliodon is considered to be a powerful tool that can aid students, professionals, building developers and users to better understand the relationship between the sun's path and its effects on the architectural model(s). Most of the heliodons are relatively expensive and complex in operation. Thus, the need to design and build a simple and relatively inexpensive one emerged. It was proposed to work on this heliodon as a team project in the environmental control class "fall-2016". The authors put the design concept and introduced a mathematical calculations table to be used with the physical heliodon, while nine students participated in the manufacturing process. The design concept is based on determining the sun's position by converting the Altitude and Azimuth angels to their corresponding measurements on the $(X, Y \& Z)$ coordinates (in relation to the observer's location). One light source can be moved on a set of graded tubes assembled in the shape of a wire frame box (thus the $X, Y \& Z$ distances could be measured) to simulate the sun's position and its lighting conditions for any latitude, at any time for any chosen day.

JOURNAL OF CONTEMPORARY URBAN AFFAIRS (2017) 1(3), 54-61.

https://doi.org/10.25034/ijcua.2018.3680
\end{abstract}

www.ijcua.com

Copyright (c) 2017 Journal of Contemporary Urban Affairs. All rights reserved.

\section{Introduction}

1. Nearly, $40 \%$ of the energy produced worldwide is consumed by buildings; this is equivalent to 2500 Mtoe "million ton oil equivalents" per one year (Attmann, 2010). In Egypt, $52 \%$ of the produced electricity is consumed only by the residential buildings, while $90 \%$ of the electric power plants depend on non-renewable energy resources to operate (URL4)(www.moee.gov.eg). Thus, buildings are considered to be one of the main causes of climate change.

Studying the sun's impact on buildings is the first step on the long way of solar-responsive design, where the most important goals are:
- The maximum harvesting of winter sun

- The optimum control of summer sun

- The benefits of the natural daylighting "The natural daylight that a $0.9 \mathrm{~m} \times 1.5 \mathrm{~m}$ window can provide is equivalent to $100-60 \mathrm{~W}$ incandescent lamps" (Lechner, 2008).

Hence, the comprehensive understanding of solar geometry and its consequences is necessary for a successful architectural design.

\footnotetext{
*Corresponding Author:

Canadian International College (CIC), Egypt

E-mail address: maged_george@cic-cairo.com
} 
Starting from the very early model made by Dufton-Bachett in 1931, passing by that one developed by George Malcolm Beal in 1953 (Beal, 1957), and till the most recent models of Lechner 2001 and his successors, heliodons have been considered one of the most powerful tools that can aid students, professionals, building developers and users to better understand the relationship between a building and the sun (Lechner, 2001).

Since heliodons have been developed mainly to study the effect of the sunlight on a given building(s) model, three main variables are always the dominant constraints for any heliodon design concept, these variables are:
- Latitude determines the relation between the sun's path and the geographical location on the earth's surface.

- Day of the year: specifies the declination of the sun on a specific day.

- Time of the day: determines the sun's position between the east and the west (Cheung, 2000).

These three variables guide the researcher to obtain two angels that help to allocate the sun's position (Figure 1). These two angels are:

- Altitude (ALT): Measured upwards from the horizon where the observer's location is at the center of the skydome.

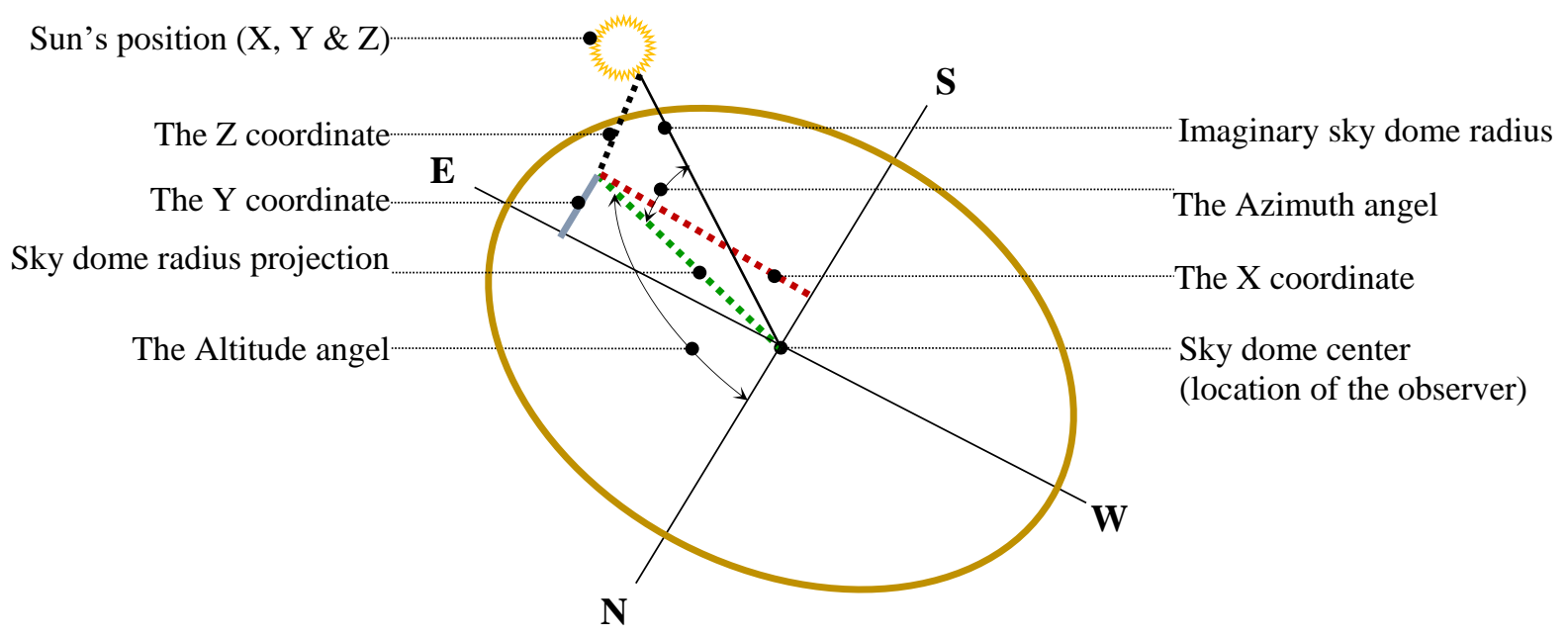

Figure 1. Converting the sun's position parameters from the angels - Altitude \& Azimuth - system to the coordinates - X, Y \& Z system.

- Azimuth (AZI): measured in the horizontal plane from north or south (Szokolay, 2008).

Heliodon designs could be classified into two groups, depending on the positions of both of the light source and the building model:

- Tilted / moving building model while the light source (s) is either fixed or moving.

- Fixed (horizontal) building model while the light source is moving (Cheung, 2011).

A quick glance on both of the two types declares that the first type has significant disadvantages: Holding the model in steep angels may result in difficulty in viewing or causing it to slide out of position. Furthermore, it doesn't simulate our everyday experience of the sun moving across the skydome. Meanwhile, the fixed building model types are complicated to manufacture and operate, relatively large (for more accuracy) thus, require larger space during operation and / or storage (most of them), and to somehow more expensive (URL3) (www.heliodon.org).

\section{The Need for This Heliodon}

Our target in the environmental control class was to encourage the students to build their own heliodon, taking into consideration that it should be easy to understand, can be constructed inside the $\mathrm{CIC}$ campus with simple tools, requires a relatively small space during both operation and storage and relatively inexpensive. To achieve the previous goals, the fixed building model type was selected; the concept of converting both of the Altitude and the Azimuth angels to their corresponding $(X, Y$ \& $Z$ ) coordinates (Figure 1) "with a moving single light source to simulate the sun's position" was chosen. The UPVC pipes and connections were proposed as a construction material for the heliodon, "relatively rigid and cheap", while the $5 \mathrm{~cm}$ thick rigid foam and $5 \mathrm{~mm}$ thick white 
cardboard were the materials for the base. Design concept and calculations, supervision and the orientation of the manufacturing process were the authors' tasks, while the construction was accomplished by a group of nine students.

\section{Solar Position Calculations}

The authors relied on external software "SunPosition" to determine the ALT \& AZI angels of the sun's position for any latitude, on any day of the year and at any time of the day. Also, to generate the necessary input data to build a calculations table that will be used in the design and manufacturing process of the heliodon(URL5) (WWW.susdesign.com/sunposition ).

The main function of the calculations table is to change the parameters of the sun's position from the "ALT and AZI angles system" to the coordinates system through a series of equations. The "SunPosition" software was chosen for two main reasons:

- It is comprehensive software, but yet, with an easy interface for students' interaction.

- It is open-source software, which can be accessed online easily and freely by students.

\subsection{The Calculations Table}

The authors designed an excel spreadsheet linked to the "SunPosition" output data file - to generate the main calculations table that will help the students to determine all the needed data and measurements to construct and operate their heliodon. The table was designed with two groups of data as follows:

\section{- The input data group (Table 1-a):}

Latitude \& Longitude: measured in degrees and generated automatically based on the value that was entered manually by the student on the "SunPosition" software to define the exact location for calculation.

Time zone: measured in hours and generated automatically based on the value that was entered manually by the student to the "SunPosition" to define the exact location for calculation.

Date of the day: a unit-less pre-set data, its values represent a predefined range of days for tracking the solar path over the year with oneday interval ( $1^{\text {st }}$. of Jan. $-31^{\text {st }}$. of Dec.).

Time of the day: a pre-set data, measured in hours, its values represent a predefined range of 13 hours for tracking the solar path over the day with one-hour interval $(06-18)$.

Zero azimuth direction (North or South): choosing North (N) or South (S) as the zero Azimuth direction (ZAD) is generated automatically based on the selection that was previously entered manually by the student on the "SunPosition", and it is set to the following rule: if the North is the zero Azimuth direction then its value $=1$ and the South value $=0$, and vice versa.

Original Altitude \& Azimuth angles: can be obtained from the "SunPosition" in correspondence with a pre-set time value; it is measured in degrees and entered manually by the student to the calculations table.

\section{- The output data group (Table 1-b):}

Absolute Azimuth angel: measured in degrees and generated automatically based on the input value of the original Azimuth angle "regardless the zero Azimuth direction".

The correction factor for the Azimuth angel: measured in degrees and generated automatically, its value is either (0 or 180) based on the input value of the Zero Azimuth Direction ( 180 in case of the ZADN=1 and 0 in case of the ZADS $=1$ ).

Corrected Azimuth angle: measured in degrees and generated automatically based on the input value of the zero Azimuth direction ( $\mathrm{N}$ or S), the output value of the Azimuth angle correction factor and the output value of the absolute angle.

Skydome radius: a pre-set data that is measured in centimeters; its value represents the maximum allowable movement distance of the light source in any direction starting from the heliodon's origin point (Observer's point).

The distances on the (Z) coordinate: measured in centimeters; it is generated automatically based on the output values of the Altitude angle / Sine and the pre-set value of the skydome radius.

The $\mathrm{Z}$ Coordinate movement direction: measured in $(+)$ only.

The distances on the (Y) coordinate: measured in centimeters, and is generated automatically based on the values of skydome radius projection on the horizontal plane and the Azimuth angle cosine.

The $Y$ coordinate movement direction: measured either in (+) or in $(-)$; its values are generated automatically based on the output values of $Y$ coordinate distance, the input values of ZAD ( $N$ or $S$ ) in addition to the output values of absolute Azimuth angel.

The distances on the $X$ Coordinate: measured in centimeters; it is generated automatically based on the output values of skydome radius projection in addition to the output values of the distance of $Y$ coordinate. 
The $x$ coordinate movement direction: measured either in (+) or in (-); its values are generated automatically based on the output values of the distance on the $X$ coordinate, the pre-set values of time, the input values of the ZAD ( $N$ or $S$ ) in addition to the input value of the original Azimuth angle.

\subsection{VALIDATION OF THE CALCULATIONS TABLE OUTPUT}

To validate the output data that was obtained from the calculations table "for specific latitude and a certain time of a certain day" it was important to compare it with a reference data for the same variables. The latitude of $30.04 \mathrm{~N}$ (Cairo - Egypt) was chosen and the hours from
$(6-18)$ for the longest and shortest days of the year (21st. of June and 21 st. of December) were selected for the validation. The output data results "the measuring distances on the $X, Y$ and Z coordinates" for Cairo - Egypt at the selected hours on the chosen days were exported to "Grasshopper"software(URL2) (http://www.grass hopper3d.com/) to generate the corresponding solar path diagrams. When the solar path diagrams generated by "Grasshopper" were compared to those generated by reference software "Sun- Path Projections" for the same variables the results were identical (Figure 2).

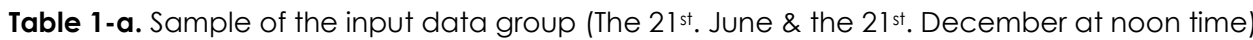

\begin{tabular}{|c|c|c|c|c|c|c|c|c|c|}
\hline \multirow{4}{*}{ Variables } & \multirow[t]{4}{*}{ Latitude } & \multirow[t]{4}{*}{ Longitude } & \multirow[t]{4}{*}{$\begin{array}{l}\text { Time } \\
\text { Zone }\end{array}$} & \multirow{4}{*}{$\begin{array}{c}\text { Date } \\
- \\
\text { Month }\end{array}$} & \multirow[t]{4}{*}{ Time } & \multicolumn{2}{|c|}{$\begin{array}{c}\text { Zero } \\
\text { Azimuth Direction }\end{array}$} & \multirow{4}{*}{$\begin{array}{c}\text { Altitude } \\
\text { Angle } \\
\text { Original }\end{array}$} & \multirow{4}{*}{$\begin{array}{c}\text { Azimuth } \\
\text { Angle } \\
\text { Original }\end{array}$} \\
\hline & & & & & & \multirow{3}{*}{\begin{tabular}{|c|}
\multicolumn{1}{|c|}{ North } \\
$" 1 "=$ Yes \\
$" 0 "=$ No \\
\end{tabular}} & \multirow{3}{*}{\begin{tabular}{|c|} 
South \\
$" 1 "=$ Yes \\
$" 0 "=$ No \\
\end{tabular}} & & \\
\hline & & & & & & & & & \\
\hline & & & & & & & & & \\
\hline Data Type & Input $(\underline{\unrhd})$ & Input $(\underline{\downarrow})$ & Input $(\underline{\Perp})$ & Pre-set & Pre-set & Input $(\underline{\Perp})$ & Input $(\underline{\unrhd})$ & Input $(\downarrow)$ & Input $(\downarrow)$ \\
\hline Units & "Degrees" & "Degrees" & "Hours" & "---" & "Hours" & "---" & "---" & "Degrees" & "Degrees" \\
\hline \multirow{2}{*}{$\begin{array}{l}\text { Values } \\
\text { Values }\end{array}$} & $30.0444 \mathrm{~N}$ & $31.2357 \quad \mathrm{E}$ & GMT 2 & \multirow{2}{*}{$\begin{array}{l}\text { 21-Jun } \\
\text { 21-Dec }\end{array}$} & $12: 00$ & \multirow{2}{*}{$\begin{array}{l}0 \\
0 \\
\end{array}$} & \multirow{2}{*}{ 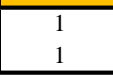 } & 083.360 & 006.260 \\
\hline & $30.0444 \mathrm{~N}$ & $31.2357 \quad E$ & GMT 2 & & $12: 00$ & & & 036.490 & 001.950 \\
\hline
\end{tabular}

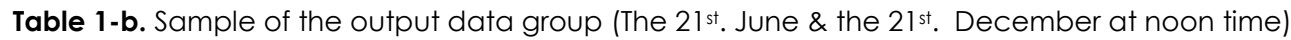

\begin{tabular}{|c|c|c|c|c|c|c|c|c|c|c|}
\hline \multicolumn{3}{|c|}{$\begin{array}{l}\text { Azimuth } \\
\text { Angle }\end{array}$} & \multirow[t]{2}{*}{$\begin{array}{c}\text { Sky Dome } \\
\text { Radius }\end{array}$} & \multicolumn{2}{|c|}{$\begin{array}{c}\text { "Z" } \\
\text { Coordinate }\end{array}$} & \multirow{2}{*}{\begin{tabular}{|c} 
Sky Dome \\
Radius \\
Projection \\
\end{tabular}} & \multicolumn{2}{|c|}{$\begin{array}{c}\text { "Y" } \\
\text { Coordinate }\end{array}$} & \multicolumn{2}{|c|}{$\begin{array}{c}\mathrm{X} " \\
\text { Coordinate }\end{array}$} \\
\hline \multirow[t]{3}{*}{ Absolute } & \multirow{3}{*}{\begin{tabular}{|c|}
$\begin{array}{c}\text { Correction } \\
\text { Factor }\end{array}$ \\
"0" / "180"
\end{tabular}} & \multirow[t]{3}{*}{ Corrected } & & Rate & \multirow[t]{3}{*}{ Direction } & & Rate & \multirow[t]{3}{*}{ Direction } & Rate & \multirow[t]{3}{*}{ Direction } \\
\hline & & & \multirow[t]{2}{*}{ Hyp. 01} & \multirow[t]{2}{*}{ Opp. 01} & & Adj. 01 & \multirow{2}{*}{ Adj. 02} & & & \\
\hline & & & & & & Hyp. 02 & & & Opp. 02 & \\
\hline Output ( $\uparrow$ & Output ( $\uparrow$ ) & Output ( $\uparrow)$ & Pre-set & Output $(\uparrow)$ & Output ( $\uparrow$ & Output $(\uparrow)$ & Output $(\uparrow)$ & Output $(\uparrow)$ & Output ( $\uparrow$ & Output $(\uparrow)$ \\
\hline "Degrees" & "Degrees" & "Degrees" & "cm" & "cm" & "+" & "cm" & "cm" & "+" / "-" & "cm" & "+" / "-" \\
\hline 006.260 & 0 & 006.260 & 100 & 099 & + & 012 & 011 & - & 001 & - \\
\hline 001.950 & 0 & 001.950 & 100 & 059 & + & 080 & 080 & - & 003 & - \\
\hline
\end{tabular}

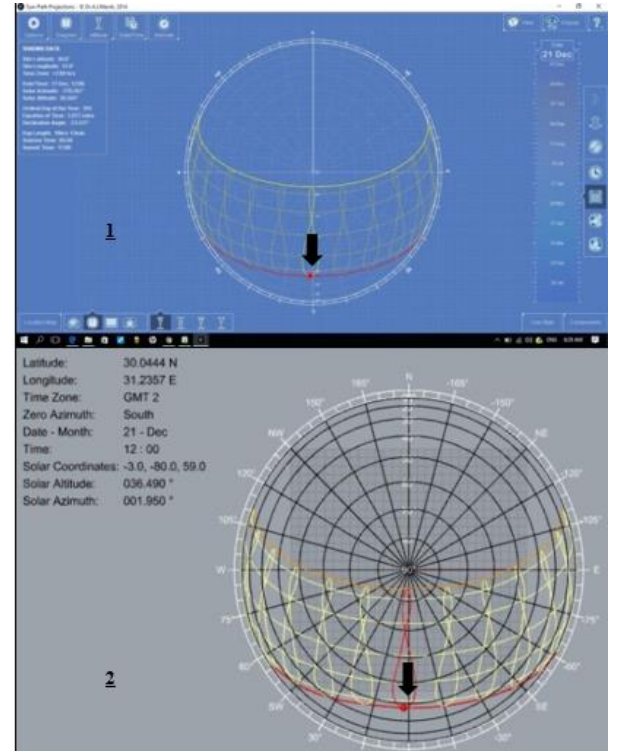

Figure 2. Output data of (Sun-Path Projections - 1 \&

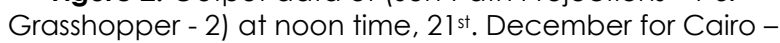
Egypt

\section{Heliodon Construction}

For the purpose of learning in the environmental control Lab., the skydome radius was selected to be $100 \mathrm{~cm}$ "this could be greater or smaller according to the available space, the required accuracy and the scale of the model(s) understudy".

The UPVC pipes were cut and assembled "with connections" to construct a wireframe like box "a bit larger to allow the light source to move $100 \mathrm{~cm}$ in the three coordinates" as shown (Figure 3 \& 7). The (Pz1, Pz2, Pz3 \& Pz4) pipes were graded $(0$ to $100 \mathrm{~cm})$ "using a sticker measuring tape" to illustrate the measuring units on the $Z$ coordinate, (Px1 \& Px2) pipes were graded from their midpoints $(0$ to $100 \mathrm{~cm}$ \& 0 to $-100 \mathrm{~cm})$ to illustrate the measuring units (+ \& -) on the $X$ coordinate and finally (Py) pipe was graded from its midpoint (0 to $100 \mathrm{~cm} \& 0$ to $-100 \mathrm{~cm}$ ) to illustrate the measuring units (+\& -) on the $Y$ coordinate. Bolts (B1, B2, B3 and B4) can be 
loosened to allow (Pxland Px2) pipes to move freely up and down on the (Pz1, Pz2, Pz3 and Pz4) pipes or can be tightened to fix them in the required $Z$ coordinate position (Figure 4). Bolts (B5 and B6) can be loosened allowing the (Py) Pipe to move feely to the right or to the left on (Px) and $P \times 2$ ) pipes

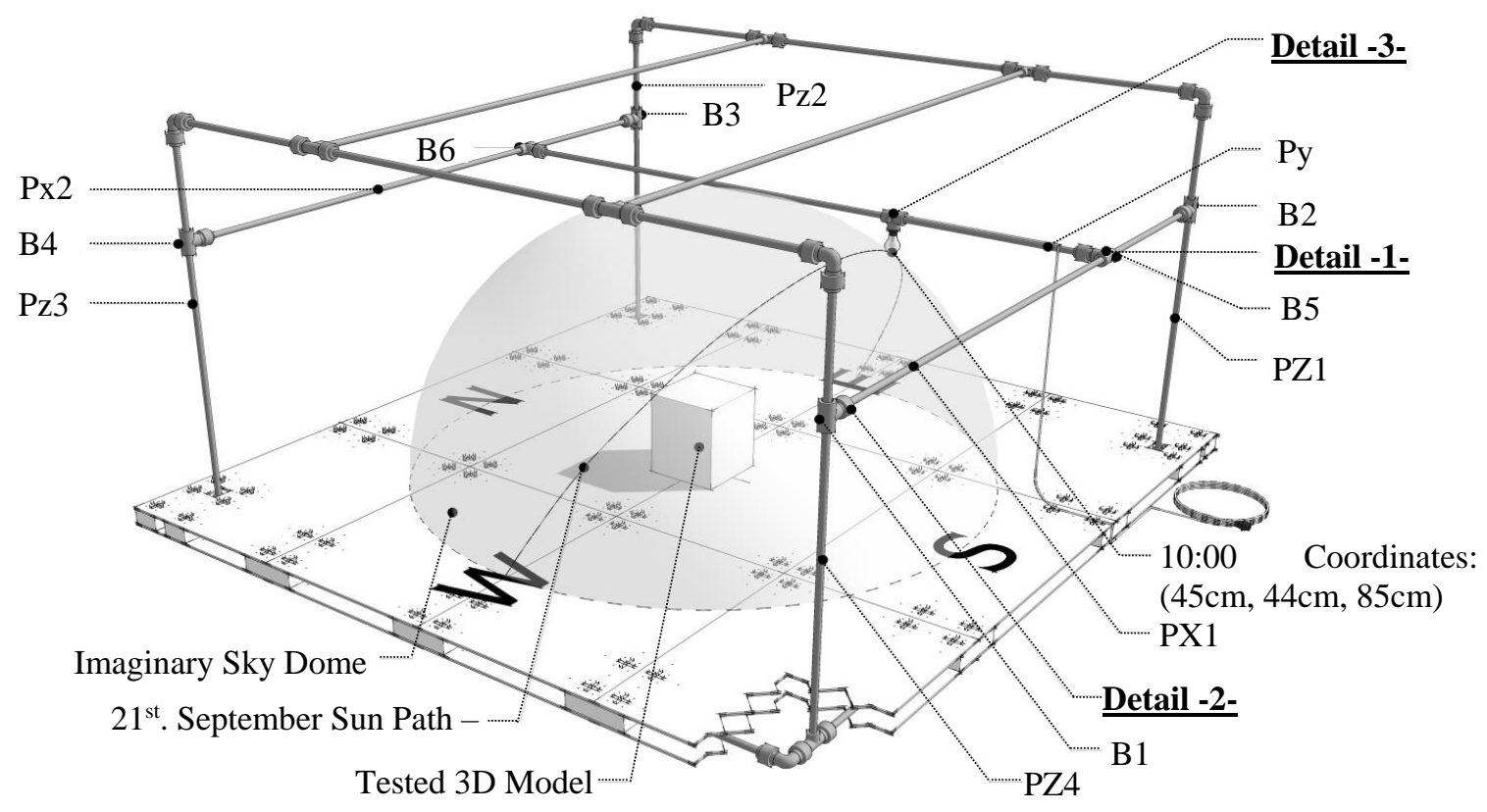

Figure 3. The proposed heliodon illustrates the effect of the sunlight on a building model .

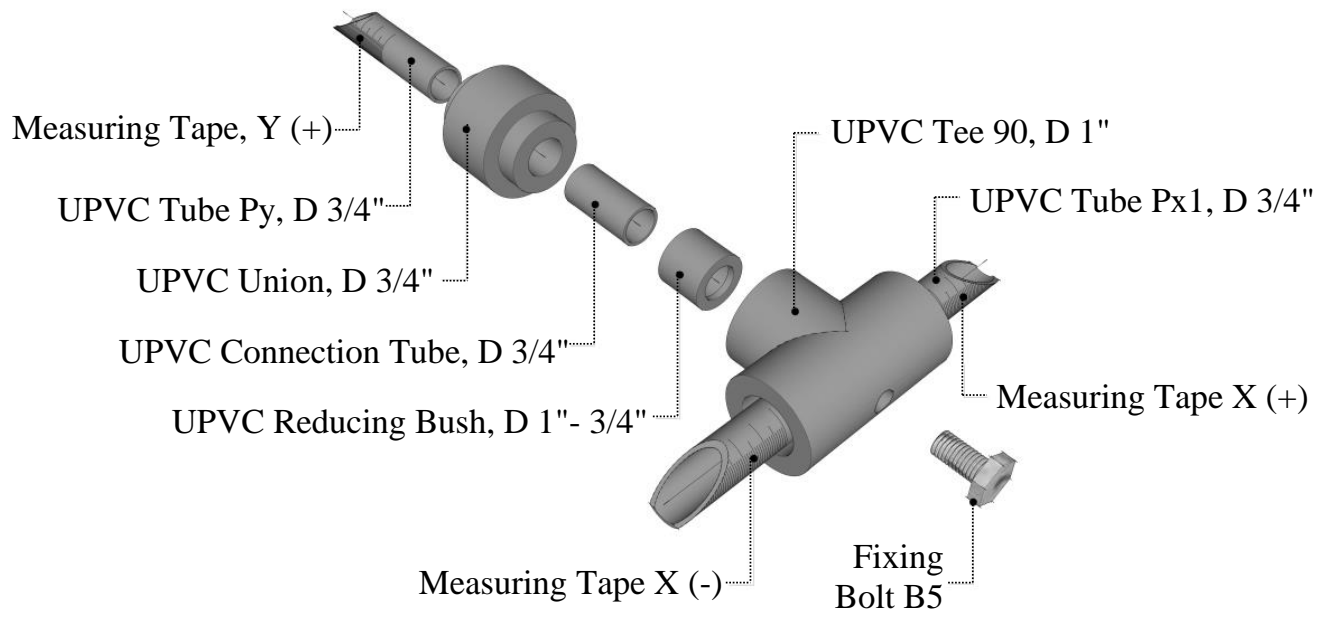

"21 $1^{\text {st }}$. September at 10:00, Cairo-Egypt"

Figure 4. Detail 1. 

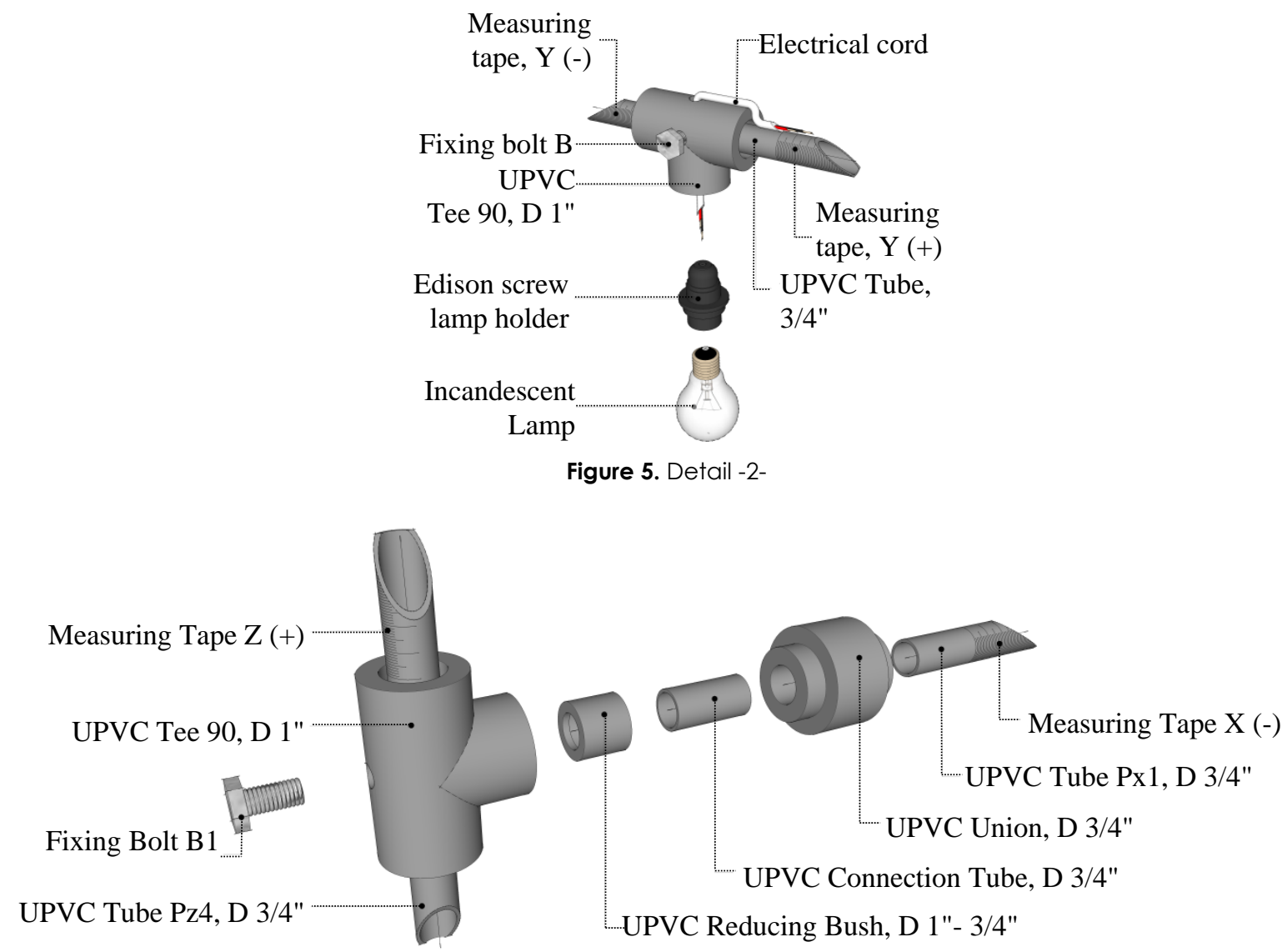

UPVC Reducing Bush, D 1"- 3/4"

Figure 6. Detail 3.

or can be tightened to fix it in the required $X$ coordinate position (Figure 5). A (100W) incandescent lamp was used as a light source to simulate the sunlight rays and it can move back and forth on the (Py) Pipe to reach the required $Y$ coordinate position and simulate the sun's position (Figure 6). The base was made of $5 \mathrm{~cm}$ thick rigid foam between two layers of " $100 \mathrm{~cm} \times$ $70 \mathrm{~cm} \times 5 \mathrm{~mm} "$ cardboard sheets.

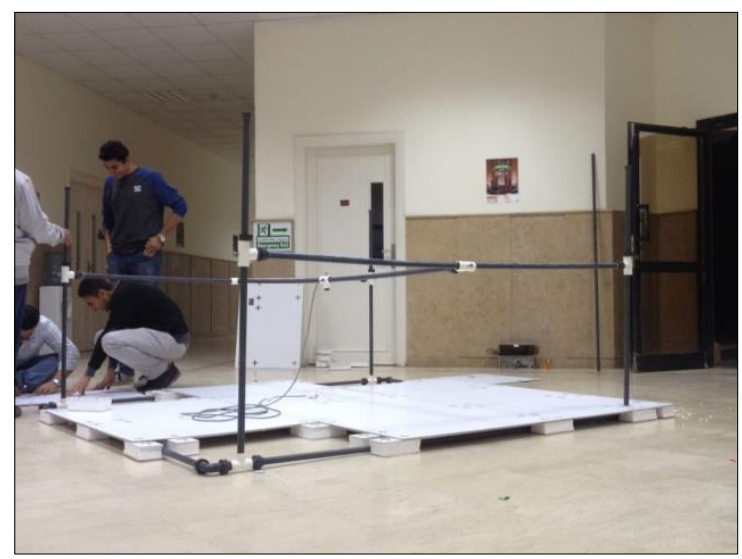

Figure 7. The students during the manufacturing and assembling of the heliodon

\subsection{Operation of the Heliodon}

After the installation process "previously described" the student can follow the next steps to track the solar path and study the effect of the sun light on his building model:

- Prepare the building model and put it in the origin point of the heliodon (the model should be oriented with respect to the four cardinal directions).

- Determine the latitude of the building, date of the day and the time of the selected day.

- Use the previous constrains as input data in the "SunPosition" software (or any similar software) to generate the corresponding Altitude and Altitude angels.

- Use all the predetermined constrains and the generated angles as input data in the designed calculations table to generate the corresponding measuring distances on the $X$, $Y$ and $Z$ coordinates.

- Adjust the position of the light source according to the generated measures on

- the heliodon. 
- Plug in the electrical cable, turn on the lamp and observe the effect of the light on the model (Figure 8).

- After completing the study turn of the lamp and unplug the electrical cable.

- In case of storage for long periods, disassemble the heliodon parts and store it.

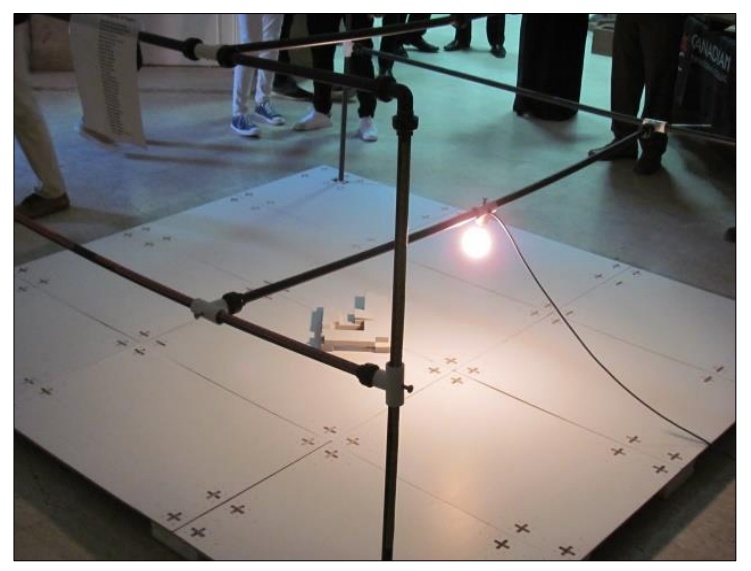

Figure 8. Using the heliodon to test the effect of sunlight on a building model

\section{Conclusion}

The main target of this work was to encourage the students in the environmental control class to participate in the design and the manufacturing of their own heliodon, hence their awareness of both of the solar geometry and the solarresponsive design could be enhanced. The concept of this heliodon is relatively simple as it depends on the determination of the relationship between the sun's position and its corresponding $X, Y$ and $Z$ coordinates related to the observer's location on the earth's surface. Relying on external software "SunPosition" was necessary to generate both of the Azimuth and Altitude angels for any location on the earth's surface and at any time for any chosen day. The designed calculations table played a vital role during both of the manufacturing and operation processes.

The Excel sheet that was designed to form the calculations table relied on the output data of the "SunPosition" (Azimuth and Altitude angels) along with the assumption of the sky dome radius to generate the corresponding $X, Y$, and $Z$ measuring distances on the heliodon. The output data of the calculations table were compared to external reference software - Sun-Path Projections - and the results were identical. Thus the design concept could be verified.

The proposed heliodon was successfully constructed according to the assumed measurements in the calculations table, and the students could use it effectively to study the effect of the sunlight on their building model(s). This heliodon could be designed and constructed with different scales according to the required accuracy; the available space and budget, and can be disassembled and stored in small space for future use.

\section{Tuning \& Future Work}

We aim to reconstruct this heliodon system with more durable material (stainless steel pipes), more efficient bracing system and a LED light source instead of the incandescent lamp to give more parallel light rays, thus, a more realistic sunlight simulation. Also, we hope we can make a fruitful collaboration with other engineering specializations to make the system fully operated and controlled by a commuter system.

\section{Acknowledgement}

We would like to give special thanks to our diligent students who participated in the construction process: Andrew Ghettany, Mahmoud El-Zayaty, Mohamed Wahba, Mohamed Ezz El-Dein, Mohamed Essam, Mostafa Helal, Omar El-Shahawai, Omar Abd ElGawad and Ziad Hassan.

Also we would like to thank those so special students of the environmental control class "Cohort-2014", a list of their names could be found on the following link: (URL1) (https://drive.google.com/open?id=0BbNxtEORp3VTUdWVXIaYIdLdVk).

\section{References}

Attmann, O. (2010). Green Architecture: Advanced Technologies and Materials. McGraw-Hill Professional, 11-13.

Beal,G.M.(1957). Natural Light and the InsideOutside Heliodon, University of Kansas publications. the bulletin of engineering and architecture, 38, 12-13.

Cheung, K.P. (2000). A Multi-Lamp Heliodon for Architectural Schools, International Journal of Architectural Science, 1 (1), 46-58.

Cheung, K.P. (2011). A Discussion on the Design Principles of a Patented Portable Direct Sunlight Light-Duty Universal Heliodon Mounted on a Camera Tripod. International Journal of Architectural Science, 8(4), 98-113.

Lechner, N. (2001). The Sun Emulator: A Conceptually Clear Heliodon. Proceedings 
of the ASCA "Association Colligate Schools of Architecture" Technology conference, 116-118.

Lechner, N. (2008). Heating, Cooling, Lighting: Sustainable Design Methods for Architects, 3rd. Ed., NY, USA, John Wiley \& Sons,.404.

Szokolay, S.V. (2008). Introduction to Architectural Science: The basis of Sustainable Design, 2nd. Ed., Elsevier, USA, 2224. URL 1
https://drive.google.com/open?id=0BbNxtEORp3VTUdWVXIaYIdLdVk

URL2

http://www.grasshopper3d.com/

URL3

http://www.heliodon.org

URL4

http://www.moee.gov.eg/english_new/EEHC_Re p/2014-2015en.pdf (pp.18 \& pp.43)

URL5

http://www.susdesign.com/sunposition/index.php 